\title{
ONU: um balanço possível
}

\section{RAMIRO SARAIVA GUERREIRO}

$\mathrm{O}$ QUE HOJE CELEbramos, o Tratado assinado a 26 de junho de 1945, em São Francisco, Estados Unidos da América, é uma extraordinária criação da sabedoria humana. Não estou pretendendo aqui começar um ditirambo, mesmo porque não haveria coro afinado que roborasse o corifeu. Pelo contrário, há compreensíveis dissonâncias na avaliação da bondade dos 111 artigos da Carta e da forma como foram cumpridos ou não cumpridos.

Não vejo, entretanto, como não se admirar de que um tratado institucional de escopo tão abrangente houvesse subsistido, válido e basicamente adequado a conjunturas tão variadas como as que tivemos no último meio-século.

Meio século que se inicia na euforia do fim da mais terrível das guerras e das tiranias mais repulsivas, para viver na tensão e no medo. Meio século de dor, mas também de criação, de paz geral que as guerras e revoluções locais punham em risco, mas não rompiam.

Muitos de nós, profissionais, éramos talvez menos sofredores (se não fôssemos de países diretamente envolvidos) porque acreditávamos que as violências localizadas eram parte de um longo processo de ajustamento. Processo do qual nasceram dezenas de nações, mudando a face da África e da Ásia, que levou a Europa Ocidental a ter certo êxito em suas tentativas de unificação, por primeira vez desde Carlos Magno. Processo que, em países reflexos, como os da América Latina, levou a situações que variavam entre o dramático e o cômico, com um ou outro toque de tragédia, mas também a novos patamares de desenvolvimento e recente maturidade.

Não foi sempre a ONU, como se pretendeu no art. $1^{\circ}, \mathfrak{S} 4$, "um centro para harmonizar as ações das nações na obtenção dos fins comuns" enunciados em seus propósitos. A própria concepção da Carta estava baseada em um entendimento consensual entre as superpotências, o que deixou de se verificar rapidamente. O meio século caracterizou-se, pelo contrário, pelo confronto entre elas, que permeou todas as atividades da Organização, direta ou indiretamente. Muito resumidamente, pode-se recordar que:

- a Organização não se tornou, nem talvez se devesse ter imaginado que se tornaria, o sistema único de convivência e acomodação dos Estados e de outros fatores nas relações internacionais; 
- sobreviviam, às vezes em posição dominante, sintomas dos sistemas históricos, isto é, o jogo de alianças (como a OTAN, o Pacto de Varsóvia, e, em certo período, o Cento), o recurso unilateral ao emprego da força (como no Vietnã, em Grenada, no Afeganistão), o emprego abundante dos meios sub-reptícios de ação (não só a espionagem, mas também o auxílio e estímulo ao terror e à guerrilha);

- mesmo nos casos de conflito armado, ou de situações que pusessem em perigo a paz, quando o Conselho de Segurança ou a Assembléia Geral os discutiam, cada parte envolvida era patrocinada por uma ou outra das superpotências e decisões efetivas eram, assim, politicamente impossíveis ou, se adotadas, freqüentemente ineficazes.

Apesar das faltas sérias e muito visíveis, é razoável dizer que o balanço da atividade da Organização na longa fase da Guerra Fria é superavitário, mesmo no que concerne à sua função essencial relativa à paz e à segurança. Funcionou ela, muitas vezes, como uma espécie de recurso para que os envolvidos em conflitos pudessem acobertar difíceis transigências e dar boa imagem, interna e externa, a decisões politicamente arriscadas de recuo na confrontação, recorrendo à luta verbal nas salas de conferência para evitar a inevitabilidade da morte e destruição do enfrentamento armado. Até que ponto isso, de certa forma, não ocorreu, por exemplo, na questão da Caxemira, permitindo às partes, sem desistirem de suas teses, encerrar um ou outro episódio guerreiro inconclusivo, sem perda da face? Quantas vezes, nas periódicas erupções militares do crônico conflito no Oriente Médio, não foi na ONU que se fizeram arranjos que permitiram evitar derrotas totais e a ameaçadora intensificação do confronto, ao ponto de elevá-lo perigosamente em nível das superpotências, criando-se condições para fases de pacificação ou de redução da tensão a patamares toleráveis? Em todo o imenso conflito da descolonização, a Organização foi não só o palco para a representação formal do drama, mas, freqüentemente, a promotora de doutrinas e o acicate das negociações.

Dizia-se que a Organização não podia tomar medidas efetivas por causa do poder de veto atribuído aos membros permanentes do Conselho de Segurança pelo art. $27, \mathfrak{S} 3^{\circ}$ da Carta, e tendo em vista a impossibilidade política de ação conjunta das Superpotências durante a Guerra Fria. Em conseqüência, deu-se interpretação ao texto segundo o qual a exigência de votos concorrentes dos cinco membros permanentes não significava votos concordantes, mas se verificava desde que não houvesse voto discordante. Isto é, a abstenção ou a ausência (como no caso da decisão do emprego da força coletiva no conflito da Coréia) permitiam a formação do consenso.

É óbvio que não estamos aqui para fazer o histórico da Organização. Esta interpretação, dita praeter legem pelos que a favoreciam e contra legem pelos que 
a ela se opunham, tem importância particular como exemplo da evolução do sentido, alcance e aplicação de um tratado institucional feito para durar. Algumas tentativas de evitar o veto, como o maior uso da Assembléia Geral, a frustrada criação da Pequena Assembléia e a Resolução Unidos pela Paz não tiveram um futuro significativo.

Mas a interpretação praeter legem do dispositivo sobre o veto também aplicou-se a muitos outros dispositivos da Carta de forma menos visível, mas não menos importante e profícua aos objetivos comuns. É o caso, por exemplo, dos direitos do homem, em que se vem criando uma normatividade que vai além do texto da Carta mas que, se gradativa e cautelosa, se manterá de acordo com seu espírito e seus propósitos. É normal e desejável que assim seja, pois a Organização deve ser viva e criativa para perdurar.

Há, entretanto, de se ter cuidado nas interpretações que se deduzem do texto, "pour les besoins de la cause", apresentando conotações incompatíveis com o contexto, o objeto e o espírito da Carta. Vimos um exemplo nas explicações que a representante dos Estados Unidos da América, Senhora Kirkpatrick, deu para justificar a ação de seu país em Grenada. Baseava-se ela no $\$ 4^{\circ}$ do art. $2^{\circ}$ da Carta, que veda o emprego ou ameaça da força contra a integridade territorial ou a independência política de qualquer Estado, ou, como diz expressamente em seguida o citado dispositivo, "de qualquer outra maneira inconsistente com os propósitos das Nações Unidas”. Bastaria, pois, que não fosse inconsistente com os propósitos das Nações Unidas para que o emprego da força fosse lícito. Não temos por quê discutir o assunto. Basta lembrar o $\$ 7^{\circ}$ do mesmo artigo, que cria a obrigação de resolver as disputas por meios pacíficos e o pretendido monopólio do uso da força pelo Conselho no quadro do Capítulo VII, com a única exceção da legítima defesa contra ataque armado, prevista no art. 51 .

Dei relativo destaque às interpretações referidas, como meros exemplos de bons e maus resultados a que podem levar, porque eles serão cada vez mais freqüentes e potencialmente graves no período pós-Guerra Fria em que estamos. A essa altura, não podemos deixar de dedicar algum tempo à reflexão sobre a nova situação mundial, a função que nela pode ter a Organização, o lugar e o papel do Brasil além de os cuidados a se ter presentes. Como toda a gente, especializada ou não, teríamos de fazê-lo às apalpadelas.

A situação pós queda do muro de Berlim tem sido comentada ad nauseam e não vou aqui ocupar tempo transmitindo informações já conhecidas por todos. Lembraria apenas que é uma situação de certo modo semelhante à do fim da Segunda Guerra Mundial ou da Primeira, à do Congresso de Viena ou da Paz de Westphalia. Apenas não é conseqüência de guerra cruenta; não houve uma debellatio, mas o desmoronamento interno e a transformação de um dos contendores. 
Aparentemente, realizou-se a precondição para o funcionamento da organização mundial, ou seja, a possibilidade de consenso, senão total ou permanente, freqüente e operacional entre os membros permanentes do Conselho de Segurança. Não pareceria, pois, haver necessidade de alteração no sistema de defesa coletiva previsto na Carta. Até certo ponto, essa visão otimista corresponderia à realidade no caso da invasão do Kuwait pelo Iraque.

Já em uma situação ambígua em que não houve invasão do território de um Estado membro por outro, mas se criou uma situação susceptível de por em perigo a paz internacional, como nos conflitos conseqüentes à decomposição da Iugoslávia, foi impossível a adoção de medidas eficazes. É natural:

- porque não se caracteriza a agressão a um Estado previamente reconhecido (caso da Bósnia);

- porque não há interesse específico (petróleo, por exemplo) como no caso do Iraque;

- nem possibilidade de mobilizar os grandes recursos militares necessários.

Cabe aqui recordar que o mundo não se tornou unipolar pelo fato de os Estados Unidos da América, como única superpotência, não terem desafiantes no campo militar. Em primeiro lugar, dificilmente podem eles agir por si sós. Não apenas porque a cobertura política da ONU é fundamental do ponto de vista de opinião pública, senão porque para operações maiores precisarão, provavelmente, de substancioso apoio financeiro de países como Japão e Alemanha, ou, no caso do Oriente Médio, da Arábia Saudita. Segundo, porque sendo a democracia que são, só podem agir quando pareça haver evidente justificativa nacional, isto é, convencimento de sua opinião pública interna. Ora, a política externa americana, na presente conjuntura mundial, não tem definições precisas como aconteceu durante a Guerra Fria com a política de Contenção. Há variações entre minimalistas, não-intervencionistas, economicistas, que não chegam ao isolacionismo, e, por outro lado, intervencionistas que chegam a achar que os direitos do homem e a democracia no mundo, e até a ecologia e outras causas nobres, são da essência da paz e segurança etc.

É, portanto, normal que as Nações Unidas tenham tomado medidas de certa forma contraditórias, pois elas refletem tais perplexidades que, aliás, não são privilégio de seu membro mais influente.

A tendência intervencionista tende justamente a favorecer interpretações da Carta potencialmente perigosas. A Carta que assinamos e ratificamos depois de aprovada pelo Congresso prevê o uso da força como último recurso para manter a paz, coibir ou derrotar o agressor. Para nenhuma outra hipótese. Apesar 
de toda a evolução do último meio século, qualquer ampliação de tais poderes institucionais que resultem na aplicação de medidas coercitivas para fins outros que não os relativos à paz e à segurança internacionais é extremamente perigosa para a igualdade soberana dos Estados, na qual se baseia a Carta e que é o broquel dos fracos.

Para que o Conselho de Segurança permita ou decida medidas coercitivas e até o emprego da força coletiva é preciso que expressa ou implicitamente considere haver "ameaça à paz, rompimento da paz, ou ato de agressão" (art. 39). Aparentemente, pois, as medidas do Capítulo VII da Carta não se poderiam aplicar por outros motivos, humanitários, por exemplo, ou para restabelecer a democracia ou outros fins desejáveis e que gozem de excelente apoio da opinião pública. No entanto, o Conselho de Segurança tem resolvido por vezes batizar uma situação de perigosa para a paz, mesmo que não o seja, a fim de adotar medidas coercitivas corretivas. Ora, quando o Conselho age dessa forma, não há, na Carta, recurso algum para a declaração de inconstitucionalidade de sua decisão. A Corte Internacional de Justiça só poderia, em tal caso, dar parecer e não sentença se a Assembléia Geral lho pedisse, o que seria politicamente inviável em tal circunstância. É como se o Conselho de Segurança fosse lege solutus, desse ponto de vista da ausência de um processo de controle da legalidade de suas decisões.

Vejamos, como ilustração, o caso do Haiti. A Organização dos Estados Americanos tem competência para considerar a interrupção do regime democrático num Estado membro. A Carta de Bogotá, ainda mais como foi emendada em Cartagena de Índias, dá ênfase à democracia representativa. A Resolução dita Compromisso de Santiago, de 1991, prevê reunião especial de Ministros para exame das interrupções dos regimes democráticos. Mas a OEA não pode adotar medidas coercitivas obrigatórias; elas são recomendadas e apenas dão cobertura à ação de cada Estado membro, desqualificando-a como ato unilateral. A rigor, sanção juridicamente obrigatória virá a existir quando entrar em vigor a prevista no Protocolo de Washington, que emenda a Carta da OEA, ao estabelecer inter alia que, baldados os esforços de negociação e conciliação, a Assembléia Geral da Organização regional pode suspender o exercício do direito de participação do Estado faltoso nas atividades da OEA.

A Organização regional, entre as medidas de pressão contra o governo de fato do Haiti, adotou um embargo comercial que foi, mais ou menos, cumprido pelos países da região. Países de outras regiões, entretanto, não se preocuparam com o assunto. A OEA, em conseqüência, por seu Conselho Permanente, pediu a cooperação da entidade universal. Esta não tem em sua Carta qualquer dispositivo relativo à democracia representativa, nem poderia ter, obviamente. Poderia talvez preocupar-se com a situação dos direitos humanos e agir de conformidade com os métodos à disposição da Assembléia, do ECOSOC e, sobretudo, da Comissão de Direitos do Homem. É evidente que embargo comercial obrigatório não 
poderia ser considerado. É muito menos ação militar. Deu-se, entretanto, em grande parte por decisão do governo norte-americano (e parece que nem sequer por pressão da maioria da opinião pública do país) o batismo da situação no Haiti como perigosa à paz internacional, para poder-se pôr em funcionamento o Capítulo viI da Carta. Nem a República Dominicana se sentia ameaçada. Os Estados Unidos tampouco tinham sua segurança ameaçada, embora fossem muito incomodados pelo crescente volume de refugiados haitianos que chegavam a suas praias.

A intervenção na Somália, sob pretextos humanitários, não somente foi ineficaz como começou a transformar-se em ação bélica sangrenta. Foi necessário recuar.

O Conselho de Segurança condena a Líbia por não entregar a julgamento, nos Estados Unidos ou na Inglaterra, cidadãos seus que os governos desses países indiciam como autores de atentado que derrubou um avião com grande número de passageiros na Escócia. Por mais que o governo líbio nos desagrade, esse tipo de ação também não parece próprio do Conselho que não é, de maneira alguma, um tribunal judiciário. É possível, e mesmo provável, que a Líbia submetesse seus nacionais, no caso, a uma jurisdição penal internacional.

Em contraste, a situação que se criou entre os Estados sucessores da antiga Iugoslávia pode ser, sim, vista como um perigo para a paz. Mas as ações coletivas ali pretendem ser apenas pacificadoras e imparciais. Ora, na verdade, uma ação militar decisiva seria de grande envergadura e implicaria necessariamente tomar partido. Não haveria, pois, voluntários para uma ação eficaz e decisiva.

Não foi minha intenção comentar aqui, senão por amostragem e muito superficialmente, a prática recente do Conselho de Segurança.

A título estritamente pessoal e sujeito a todas as objeções, procurando apenas um pouco de clareza no quadro incerto das tendências institucionais e normativas, arrisco-me a algumas reflexões. São estas dominadas por uma abordagem partindo da avaliação do que seriam a situação e os interesses do Brasil no contexto internacional.

- Não há previsão, nem necessidade premente, de uma conferência institucional para redefinir a Organização das Nações Unidas ou substituí-la.

- A Carta tende a ser adaptada a novas circunstâncias e novas pressões da opinião mundial por meio de interpretações e é importante que o Brasil influencie as tendências interpretativas. Daí, entre outras razões, a acrescida importância da presença no Conselho de Segurança.

- Ao Brasil interessa que alterações substanciais institucionais e normativas 
sejam feitas por negociações claras das quais participe, que sejam nacionalmente discutidas e, sempre que adequado, objeto de tratados, aprovados pelo Congresso e não pelos azares de resoluções e decisões de órgãos que extrapolem suas respectivas competências e nos quais não tenha o país influência suficiente.

- O Conselho de Segurança tem os excepcionais poderes previstos no Capítulo VII para o fim específico de prevenir guerras prováveis ou terminar com elas. É prudente que utilize seus poderes para esse fim específico e não para suprir insuficiências dos meios de ação coletiva que visem à proteção dos direitos do homem, à ecologia, à restauração da democracia representativa, aos fins humanitários etc. Todos esses objetivos são fundamentais para as Nações Unidas, exceto a democracia representativa que é uma obrigação regional da OEA. Mas a Carta não previu o uso de meios coercitivos para alcançá-los, a não ser em casos excepcionais nos quais a violação dos compromissos nesses campos esteja associada à ameaça à paz, ou ao rompimento da paz, o que não acontecerá as mais das vezes. Certamente, convém ao Brasil esforçar-se pelo desenvolvimento dos meios próprios de ação internacional em prol desses objetivos, que são nossos também, estão, digamos, internalizados em nossas Constituição e leis e são aspirações nacionais. Convém, porém, fazê-lo de forma a evitar que, em nível internacional, sirvam eles de pretexto para fins espúrios, intervenções, afetem negativamente a cooperação econômica e financeira, criem obstáculos ao acesso a mercados etc.

- É de toda prudência que se vejam com clareza e objetividade os limites da ação possível das Nações Unidas no emprego da força militar. Cada vez mais será difícil ao Brasil furtar-se sistematicamente a participar de tais ações, embora possa e deva ter políticas que discriminem o que aconselharia seu apoio ou sua reserva ou abstenção. Há três situações diferentes, a definir com certa precisão, que determinam reações diferentes:

a) as chamadas forças de paz, criadas no contexto do Capítulo VI, que trata da solução pacífica de controvérsias, e só fazem sentido quando consensuais, isto é, quando os atores em confronto as desejam; se, no curso do tempo, mudam eles de atitude, cabe retirá-las, como aconteceu na fronteira entre Israel e Egito em 1967, e não mantê-las em posição ambígua e ineficaz como acontece na Bósnia, onde nem servem à paz, que não é desejada pelas partes, nem têm capacidade para impô-la;

b) a ação militar, conforme diz o art. 42, "para manter ou restaurar a paz e a segurança internacionais". As sanções do Capítulo VII em seu último estágio significam uma guerra entre as Nações Unidas e o agressor, e não podem ter a função simplesmente de afastar contendores; ao contrário das forças de paz, esse tipo de ação não é imparcial;

c) a participação em forças de paz pode até ser aconselhável quando se destinem a atuar em áreas relevantes para o Brasil, com as quais o país tenha ligações significativas, contanto que sua presença seja consensual e não vista como 
favorecimento a determinada parte em controvérsia e, ainda, se para tanto nos tivermos preparado adequadamente, inclusive do ponto de vista de treinamento militar especializado.

Os citados pontos podem dar uma impressão muito restritiva. Não é o que pretendemos. Visam, apenas, a identificar o que é e deve ser cumprido e distingui-lo do que talvez deva ser e possa ser objeto de futuras negociações. Por exemplo, se limitamos o escopo da ação militar coletiva, como ignorarmos o clamor público pela ajuda às vítimas de massacres étnicos, genocídio e outros fatos extremos de crueldade coletiva por parte de atores governamentais ou sectários? É difícil saber exatamente o que fazer. Creio que se deve levar em conta alguns pontos pertinentes: não é possível às Nações Unidas por si mesmas ou dando cobertura a seus membros mais poderosos, funcionar como polícia do mundo, tendo em vista a extrema heterogeneidade dos seus Estados-membros; fazê-lo poderia, em muitos casos, simplesmente impedir a solução de conflitos internos pela vitória de um contendor, mantendo os grupos em permanente condição de continuar a luta; a Cruz Vermelha e outras organizações puramente humanitárias devem ter todo o apoio e preferência até esgotarem todas as suas possibilidades. Apesar disso, ainda sobra um espaço de dúvida. É muito difícil, em certos casos, manter uma indiferença olímpica. Creio, porém, que isso não é razão para forçar e deformar a Carta. Caberia, talvez, propor um estudo cuidadoso de certas intervenções coercitivas pontuais, limitadas, que possam ter êxito em atenuar sofrimentos e permitir a fuga ordenada e a recolocação de vítimas de grandes perseguições. Creio que a França teve alguma experiência nesse gênero de ação tópica, isolada, que merecia análise. Seria o caso de propugnarmos a discussão ordenada de tais experiências no âmbito das Nações Unidas, com a estreita colaboração da Cruz Vermelha.

Outro exemplo é a questão de uma jurisdição penal internacional, a que a Comissão de Direito Internacional das Nações Unidas tem dedicado considerável atenção. Quando jovem $3^{\circ}$ Secretário, tive de pensar no assunto em um grupo de trabalho do Comitê para a Codificação e Desenvolvimento do Direito Internacional que, em 1947, foi encarregado inter alia de preparar uma minuta de projeto de consolidação da carta e da experiência do Tribunal de Nuremberg. Em 1948, na Assembléia Geral, assessorei nosso representante na Sexta Comissão, o Embaixador Gilberto Amado, na negociação do texto final da Convenção para a Proscrição do Crime de Genocídio. Na ocasião, Donnedien de Vabres, delegado da França e que havia sido um dos promotores no processo de Nuremberg, propôs a criação de jurisdição penal internacional para julgar o genocídio e outros crimes contra a humanidade ou a paz que seriam definidos em futuras convenções. A idéia, generosa embora, nos parecia então impraticável. Passados tantos anos, vejo, porém, em caráter pessoal, viabilidade e mesmo significativos argumentos em favor da criação de uma jurisdição penal internacional: se houver vitória, uma guerra ou revolução, pode até ser do interesse do 
vitorioso submeter os derrotados a julgamento por corte internacional preexistente do que julgá-los por órgão interno que será sempre suspeito; quando um país recusa extradição de um acusado de crime internacional, por ser nacional ou por outro motivo, poderá aceitar, contudo, o julgamento por tribunal internacional imparcial, sem desmedro de sua soberania ou posição política; em muitos casos de crimes de inegável origem e efeito internacional, mesmo que não sejam crimes internacionais strictu sensu, pode ser útil e aceitável nas convenções que os definam prever o eventual recurso à jurisdição penal internacional etc. O mínimo que se pode dizer é que o assunto merece hoje estudo e negociação em nível intergovernamental, embora haja ainda países que se vêm opondo a seu trato fora da Comissão de Direito Internacional.

Poderíamos, evidentemente, prolongar a lista dos temas importantes que podem e devem ocupar a atenção das Nações Unidas com vistas a seu aperfeiçoamento. O importante, me parece, é não partir da falsa impressão de que a paz que se sucede à Guerra-Fria permite realizar todos os projetos e atingir todos os objetivos desejáveis por uma espécie de facilitário, por intermédio de resoluções e decisões coletivas ou, pior ainda, por arranjos entre os mais poderosos. Importante é ter claramente a visão de que afirmar, como está de moda, que a soberania dos Estados tende a ser progressivamente restringida até tornar-se obsoleta é uma abordagem simplista e perigosa. Tais objetivos desejáveis só poderão ser positivamente promovidos e tais restrições à soberania, quando indispensáveis, só deverão ocorrer com a racional decisão dos Estados. A opinião pública eficiente, pelo menos nos países maiores e de personalidade definida, é a interna. Enquanto não for ela mobilizada conscientemente, não há base para mudanças sólidas e duráveis na posição externa dos Estados. Em um livro semiclandestino, publicado em 1992, disse que "ou a democracia é um processo endógeno ou não dura muito". O mesmo diria da observância dos direitos do homem, ou da preservação da ecologia. Tais aspirações podem ser apoiadas do exterior, sobretudo pelos bons exemplos e ajuda nas áreas cultural, financeira e técnica amistosa, mas não podem ser atendidas por ação externa coercitiva, que só serviria para exacerbar nacionalismos, ou dar pretexto a pressões unilaterais espúrias.

Ramiro Saraiva Guerreiro, embaixador, foi ministro das Relações Exteriores do Brasil.

Palestra feita pelo autor no Colóquio Carta de São Francisco: 50 anos depois, organizado pela Área de Assuntos Internacionais do Instituto de Estudos Avançados na Sala do Conselho Universitário da USP no dia 23 de junho de 1995. 